\title{
Replacement Therapy with Glu-Plasminogen for the Treatment of Severe Respiratory and Auditory Complications of Congenital Plasminogen Deficiency
}

\author{
Klaus Tenbrock ${ }^{a}$ Sylvia Lehmann ${ }^{a}$ Simone Schrading ${ }^{b}$ John Moran ${ }^{c, d}$ \\ a Department of Pediatrics, Division of Pediatric Pulmonology, Allergy and Immunology, RWTH Aachen University,

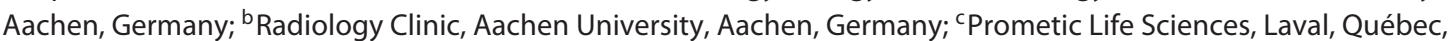

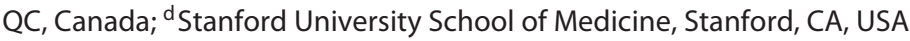

Congenital plasminogen deficiency is a rare disorder associated with extravascular formation of fibrin-rich ligneous pseudomembranes on mucosal surfaces caused by a variety of mutations in the plasminogen gene $P L G$, located at $6 \mathrm{q} 26$, and is inherited in an autosomal recessive manner [1]. These lesions may impair normal organ function, especially when they occur in the brain (hydrocephalus), conjunctivae (vision loss), ear (hearing loss), or tracheobronchial tree (airway obstruction) [1-3]. The most serious manifestations typically occur in infants and young children $[1,4]$.

Plasminogen is the zymogen of plasmin, a pivotal enzyme in the fibrinolytic pathway involved in both intravascular and extravascular removal of fibrin [5]. Several treatment approaches have been tried with varying success, including surgery and topical and systemic agents [1-4]. Surgical excision of fibrinous lesions offers acute improvement but is often associated with regrowth of the lesions $[2,4]$.

Here, we describe the case of an adolescent patient with a plasminogen activity below $10 \%$. Genetic testing showed a heterozygous Q540X (Gln 540 Stop) mutation
[1], a second mutation was not identified. As a neonate, he developed ligneous conjunctivitis, gingivitis, and obstructive hydrocephalus, which required ventriculoperitoneal shunt placement. Due to severe fibrinous plaques in the abdomen, a ventriculo-biliary shunt was inserted at the age of 3 . His ligneous conjunctivitis was treated with heparin eye drops and intermittent local corticosteroid use. He developed chronic mixed obstructive and restrictive lung disease with recurrent pneumonia and atelectasis that prompted treatment with inhaled corticosteroids, intermittent highdose systemic corticosteroids during exacerbations, continuous low-dose systemic corticosteroids, prophylactic antibiotics, and daily physiotherapy. The therapy resulted in an intermittent cushingoid appearance and growth retardation below the 10th percentiles. Tracheobronchial endoscopies showed sublaryngeal and endobronchial granulomatous material. The introduction of inhaled heparin at 7 years of age stabilized his respiratory situation. At 8 years of age, he developed chronic abdominal pain requiring treatment with omeprazole and ursodesoxycholic acid, operative readjustment of the ventriculo-biliary shunt, and finally psychotherapy due to depressive symptoms without long-standing benefit.

At 16 years of age, he developed pneumonia due to Pseudomonas that resulted in a severe reduction of his lung capacities and bilateral acute otitis media leading to progressive hearing loss due to ligneous deposits in the middle ear, unresponsive to $\mathrm{T}$ tubes and local corticosteroid treatment. His weight fell below the 3 rd percentile. At this time, compassionate use therapy with Glu-plasminogen was initiated at a dosage of $6 \mathrm{mg} / \mathrm{kg}$ body weight every 3 days. Plasminogen activity levels were $83,71,62$, and $35 \%$ at $1,6,24$, and $48 \mathrm{~h}$, respectively, after the first infusion. The regimen was kept at three infusions per week during the initial 6 weeks. Currently, he is being treated with a once-weekly infusion.

Under plasminogen replacement, the forced expiratory volume in $1 \mathrm{~s}\left(\mathrm{FEV}_{1}\right)$ rose from 64 to $87 \%$ (Fig. 1), maximum expiratory flow at $25 \%$ of the forced vital capacity increased from 20 to $54 \%$, and the forced vital capacity increased from 70 to $89 \%$ of the predicted value. There was a

\section{KARGER}

(c) 2019 S. Karger AG, Basel

E-Mail karger@karger.com

www.karger.com/aha
Prof. Dr. med. Klaus Tenbrock

Department of Pediatrics, Division of Pediatric Pulmonology, Allergy and Immunology RWTH Aachen University, Pauwelsstrasse 30

DE-52074 Aachen (Germany)

E-Mail ktenbrock@ukaachen.de 
Fig. 1. Forced expiratory volume in $1 \mathrm{~s}$ $\left(\mathrm{FEV}_{1}\right)$ before and during plasminogen replacement therapy with human Glu-plasminogen.

dramatic increase in ventilated lung areas as measured by electric impedance tomography. Treatment with low-dose systemic corticosteroids and inhaled heparin was stopped after 12 weeks. The hearing loss (50 dB) completely resolved, with impressive improvements observed in audiology testing. Furthermore, the abdominal pain resolved. He gained $7.5 \mathrm{~kg}$ of weight over a 10 -month period. His body mass index increased from 17 to $19.1 \mathrm{~kg} / \mathrm{m}^{2}$. Furthermore, a retrospective scoring on a 10-point patient global assessment using a visual analog scale (where 0 is no response and 10 is best response) showed an improvement

\section{References}

Glu-Plasminogen for Severe Congenital Plasminogen Deficiency

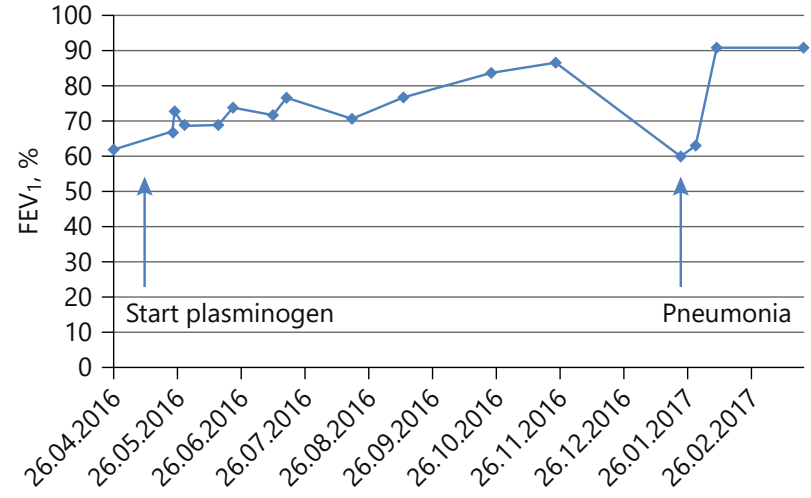

from 3 points to 9 points following plasminogen therapy. No adverse events have been associated with the use of plasminogen. The patient has been able to continue his academic studies and will start to commence a university degree in the near future.

In conclusion, this case demonstrates the clinical benefits of replacement therapy with Glu-plasminogen in an adolescent patient suffering from severe respiratory and auditory manifestations of congenital plasminogen deficiency. This patient continues to receive Glu-plasminogen on a compassionate-use basis.

1 Tefs K, Gueorguieva M, Klammt J, Allen CM, Aktas D, Anlar FY, et al. Molecular and clinical spectrum of type I plasminogen deficiency: A series of 50 patients. Blood. 2006 Nov; 108(9):3021-6.

2 Mehta R, Shapiro AD. Plasminogen deficiency. Haemophilia. 2008 Nov; 14(6):1261-8.

3 Schuster V, Hügle B, Tefs K. Plasminogen deficiency. J Thromb Haemost. 2007 Dec;5(12): 2315-22.

\section{Statement of Ethics}

Treatment was approved by the regional government of Cologne (Bezirksregierung Köln)(DE_NW_04_MIA_2017_2016).

\section{Disclosure Statement}

K.T., S.L., and S.S. have no conflicts of interest, J.M. is an employee of Prometic Life Sciences.

4 Schuster V, Seregard S. Ligneous conjunctivitis. Surv Ophthalmol. 2003 Jul-Aug; 48(4): 369-88.

5 Castellino FJ, Ploplis VA. Structure and function of the plasminogen/plasmin system. Thromb Haemost. 2005 Apr;93(4):647-54. 